\title{
Managing Online Trolling: From Deviant to Social and Political Trolls
}

\author{
Madelyn R. Sanfilippo \\ New York University \\ mrs771@,nyu.edu
}

\author{
Shengnan Yang \\ Indiana University \\ yang290@,iu.edu
}

\author{
Pnina Fichman \\ Indiana University \\ fichman@indiana.edu
}

\begin{abstract}
Trolling behaviors are extremely diverse, varying by context, tactics, motivations, and impact. Definitions, perceptions of, and reactions to online trolling behaviors vary. Since not all trolling is equal or deviant, managing these behaviors requires context sensitive strategies. This paper describes appropriate responses to various acts of trolling in context, based on perceptions of college students in North America. In addition to strategies for dealing with deviant trolling, this paper illustrates the complexity of dealing with socially and politically motivated trolling.
\end{abstract}

\section{Introduction}

Trolling is often characterized as a deviant behavior with negative impacts on online communities. Trolling events that target stigmatized groups [e.g. 1, 2] or cause harm [e.g. 3, 4] are well documented. However, some trolls are ideologically driven [4], seeking to draw attention to social problems or to support socially or politically marginalized groups [5]. Thus, since not all trolling is equal or deviant, managing these behaviors requires context sensitive strategies.

\section{Background}

Trolling has been described as "The art of deliberately, cleverly, and secretly pissing people off" [6], "a game about identity deception, albeit one that is played without the consent of most of the players" [7], and "playful mastery of Internet lore and practice that outstrips that of my target" [8]. These definitions reflect a spectrum of perspectives on trolling behaviors, from an act of deviance to a form of comedy. While some definitions reflect acceptance of these behaviors, many scholarly definitions are condemnatory [e.g. 1, 9, 10, 11]. Thus, diverse behaviors are lamped together under the term 'trolling' while scholarly and public discourse includes disagreement about applicability of the term. For the purposes of this paper, recognition that trolling is applied to many provocative, pseudo-sincere, or disruptive behaviors, ranging from socially positive to socially negative, serves as a foundation from which to explore how to assess and respond to specific behaviors in context. Trolling has been explained as a set of diverse pseudo-sincere behaviors that draw attention, ranging from anger at provocation to appreciation of humor to recognition of serious opinions communicated $[5,12]$.

Online trolling behaviors vary by context [e.g. 5, 13], with respect to platforms, communities, and events or experiences that may trigger instances of trolling [e.g. 14]. A wide range of motivations triggers online trolling [e.g. 10, 15, 16]. Some trolls are in it for the lulz or seeking to escape boredom [e.g. 17, 18], others are ideological [e.g. 19, 20], social [e.g. 21], or even malevolence [e.g. 4], as in many cases of RIP trolls and griefers [22, 23]. In this sense, what is and is not trolling is local and contextual; one definition cannot encompass all that is trolling and all examples of trolling are not the same. Specific sub-types exist, thus supporting the development of a multi-dimensional framework, sensitive to motivations and contextual perceptions, to better describe unique behaviors [5].

Social and political trolls, for example, appear to have considerable prominence, yet they have not received much scholarly attention until recently [8]. Socially motivated trolls include those seeking belongingness or esteem [e.g. 21, 24] or those who are engaged in social negotiation regarding equality or community boundaries [21]. These trolls are viewed both positively [8] and negatively [23, 25], depending on whether their objectives are seen to be legitimate or rational [e.g. 26]. Political trolls represent one form of ideological troll. Tactics in political trolling range from partisan baiting of ideological opponents into arguments, as on news forums and comments sections [27], to coordinated efforts to spam or overwhelm online platforms through civic demonstrations, as in cases like the Federal Communications Commission [FCC] comment board for net neutrality changes [e.g. 28] or the Di-Ba Expedition [29]. Scholars studied political trolls targeting President Obama [30], associated with the Occupy movement [31] or 2011 London riots [32], and generating discussions about 
latent social issues, such as race [e.g. 33], age [34], gender [35] and sexuality [34, 35].

Responses to trolling are as diverse as the behaviors themselves, with both preventative and remedial interventions [36]. Popular wisdom that trolls ought always to be ignored, however, continues to be purveyed [e.g. 9, 37]; yet the public often engages with trolls despite these warnings [e.g. 1, 2, 37]. In this sense, experiences, rather than theory, appear to inform management strategies. Furthermore, trolling is increasingly pervasive [38], indicating that efforts to stop trolls are relatively unsuccessful. Thus, there is a gap between scholarly understanding, public practice, and desired outcomes that supports the development of appropriate responses to trolling. Specifically, there is a need to consider non-deviant, social and political trolling.

Desire for effective management of trolling has been documented. There has been public outcry surrounding memorial page trolling [22], for example, which leads many to demand a mechanism for prevention or remediation. Specifically, many people are concerned about real-life consequences [25]. Ethical concerns about trolling are raised within discussions about consequences. In emphasizing the enforcement of community norms as ideal and desirable, many consider trolls to be unacceptable disruptions for corporate brands and communities [9]. Likewise, Wikipedia sysops, who invest a significant amount of time and effort fighting against vandalism and online trolling, have very negative perceptions of trolls [4]. Condemning unacceptable behavior is frequently a response to deception and those seeking to belong in a community use it intensely [39]. Those with the highest vested interest in a community active participants, commercial sponsors, and new members seeking to be included - are more likely to perceive deviant behavior as an egregious problem [9, 39]. Thus not only do outstanding questions about experience with and management of trolling exist, but so too can questions be raised about the ethics of managing trolling and the values reflected in particular management strategies.

Furthermore, it is important to manage trolling behaviors that are perceived to be deviant, given the potential for these behaviors to damage online communities [e.g. 40, 41, 42, 43]. However, given that all trolling behaviors are not viewed negatively, it is important to articulate management strategies for socially positive online trolling behaviors. It is possible to imagine different responses to trolls, in which management strategies supported socially positive or valuable behaviors and discouraged or punished the opposite, rather than seeking to prevent all trolling behaviors. For example, many hacking behaviors are perceived as malicious because individuals seek financial gain [40], and as a result, technical solutions are taken to safeguard corporations from them. Yet hacktivists, as individuals who engage in hacking for political and ideological purposes, are not viewed as equivalents, and thus are responded to differently [e.g. 44]. This raises an additional question, as to whether responses to ideological trolling should differ from other management strategies.

This study seeks to identify North American college students' perceptions of effective and ethically appropriate reaction strategies to online trolling.

\section{Methodology}

Data was collected through two focus groups and four interviews conducted with a total of 10 college students, from a large public research university. Three participants were graduate students and two were female. Focus groups and interviews were semistructured. A set of open-ended questions and case studies structured discussions, while probing and follow-up questions were tailored to allow participants to share unique experiences. All discussions were audio recorded and transcribed.

Participants were presented with seven cases capturing trolling scenarios, represented through screen shots printed on paper. Cases spanned the following platforms: Amazon, Wikipedia, Facebook, Twitter, $\mathrm{CNN}$, and the interactive chat feature on the Church of Latter Day Saints website. Scenarios also reflected differences in humorous, social, and political themes, as well as group versus individual trolling, anonymous versus identified trolls, and personal versus organizational actors. While in this paper we report general recommendations for trolling management strategies, we focus attention on social and ideological trolling case from Facebook, and on relevant ethical considerations. This case involves pseudo-sincere and satirical Facebook posts in response to Texas Governor Rick Perry's controversial statements on women's reproductive rights; as such it exemplifies social and politically motivated trolling.

Participants were also presented with a list of questions and this paper specifically examines their responses to the following questions, as pertain to individual cases:

- How would you respond to this?

- How should a moderator/administrator/site owner respond? And

- What should the community as a whole do in response to this behavior?

These questions allow for examination of perceptions of appropriate responses to trolling behaviors. 
Analysis of participant responses was based on manual coding of discussions. Specific codes that are applicable to this paper are presented in table 1. Codes were applied to comments, rather than discussions or smaller units of analysis, as often as relevant. Coding, overall, was assessed for inter-rater reliability between two coders; after multiple iterations of codebook revisions, the final coding scheme was accepted when simple agreement was at least $95 \%$ for each code and all Cohen's Kappa coefficients were between 0.81 and 1 , indicating near perfect agreement.

Table 1. Selected Codes Supporting Analysis of Responses

\begin{tabular}{|c|c|}
\hline CODE & DEFINITION \\
\hline $\begin{array}{l}\text { Activism or } \\
\text { ideology }\end{array}$ & $\begin{array}{l}\text { Discussion of activism or ideology } \\
\text { (including social, religious, or } \\
\text { political) as pertains to motivations } \\
\text { for trolling. This includes desires for: } \\
\text { 1) community and social change for } \\
\text { civil rights, 2) political changes, 3) } \\
\text { technology as a savior or } \\
\text { technological utopianism, and 4) civil } \\
\text { liberties. Hacktivism and political } \\
\text { trolling are strongly associated with } \\
\text { these motivations. }\end{array}$ \\
\hline Communities & $\begin{array}{l}\text { Discussion of how particular } \\
\text { communities are impacted by trolling, } \\
\text { encourage trolling, manage behaviors, } \\
\text { are impacted by trolling, or support } \\
\text { trolls. }\end{array}$ \\
\hline Experience & $\begin{array}{l}\text { Discussion of particular experiences } \\
\text { trolling, being trolled, or interacting } \\
\text { with communities around trolls. }\end{array}$ \\
\hline $\begin{array}{l}\text { Institutions } \\
\text { and } \\
\text { Organizations }\end{array}$ & $\begin{array}{l}\text { Entities involved in online deviant } \\
\text { behaviors that are organizations rather } \\
\text { than individuals. This also pertains to } \\
\text { organizations and companies that } \\
\text { must react to or intervene with respect } \\
\text { to trolling, in recognizing how they } \\
\text { are impacted by trolls. }\end{array}$ \\
\hline $\begin{array}{l}\text { Intervention } \\
\text { and } \\
\text { Governance }\end{array}$ & $\begin{array}{l}\text { Discussion of how to deal with the } \\
\text { result of certain deviant behaviors, } \\
\text { including who take the responsibility, } \\
\text { whether or not to interfere, how to } \\
\text { react. }\end{array}$ \\
\hline $\begin{array}{l}\text { Lack of } \\
\text { accountability }\end{array}$ & $\begin{array}{l}\text { Discussion of how the lack of } \\
\text { accountability for online behaviors } \\
\text { enables individuals to act without fear } \\
\text { of consequences and lowers costs in } \\
\text { the calculus of rational behavior. }\end{array}$ \\
\hline $\begin{array}{l}\text { Perception } \\
\text { and Attitude } \\
\text { toward }\end{array}$ & $\begin{array}{l}\text { Discussion of how individuals, } \\
\text { groups, or society perceive online } \\
\text { behaviors. }\end{array}$ \\
\hline Reaction & Discussion \\
\hline
\end{tabular}

groups, or society react to particular behaviors.

\section{Results}

Results are presented in three sections. Section 4.1 discusses recommendations, based on participants' experiences, to deal with deviant trolling, while section 4.2 outlines ethical considerations in managing trolling, as well as ethical implications of management. Section 4.3 discusses interesting results related to a specific case of ideological trolling.

\subsection{Recommendations for managing trolling}

Management strategies and preferences regarding interventions in specific circumstances were dependent upon the context, including platform, of the trolling act and whether the act of trolling itself was seen to be deviant. Participants perceived diversity in trolling and thus argued that behaviors should not be treated as if they were equivalents. The implication, affirmed explicitly in participant responses, is that while common wisdom to ignore trolls may be suitable for simple cases, more thoughtful interventions are often necessary. Strategies to deal with deviant trolling behaviors include, for example, blocking trolls and deleting their posts, unmasking their identities, ignoring them, and setting up strict rules or a peer review system to closely monitor their behaviors. There was recognition, however, that constructing responses is difficult. As participant $\mathrm{J}$ explained, "There's no great way to react to or deal with them. It's kind of why trolling is a problem".

Recommendations emphasized the desirability of mitigating deviance, while allowing creative and humorous behaviors to persist. For example, participant $\mathrm{C}$ discussed the need to differentiate between online trolling behaviors:

...if someone is really, like insulting someone ...then ... maybe they have crossed the line... But, in something like Twitch, which everyone's trolling, some people do go further than others and their comments are removed by moderators who I don't know how they can click that fast because those comment streams are just pheew... but it really is dependent on the situation and what is being said.

Context dependent responses were perceived to be most appropriate. However, feasibility of effectively managing trolling was questioned. Participants recognized challenges in designing both specific responses and institutions to discourage or structure 
responses to trolling. Participant A discussed responsibilities of moderators and administrators to block trolls or delete their posts, suggesting that:

it depends. The medium and the form of a post or a poll, given as such on a news site or someone asking for feedback on stuff, stuff that's outlandish would need to be moderated because it ends up starting a storm. Garbage that derails from the original conversation would, what that is is often objective, would need to be deleted. There's no point... as long as there's not severe name calling or threatening or really stupid, dangerous comments being thrown around, I don't think that it's necessarily needed. Because stuff like that, like a forum for a news site or a Facebook poll asking for your opinion on something or on a news site, your asking for this. But if there's someone that's just mostly giving problems or that they know is going to get a reaction, then a moderator should step in... But on something that's large scale, it's not... feasible and it's not possible because anyone can make an account. But yeah, the small forums that aren't Facebook or Twitter, it's easier because you can just IP-ban them or do something like that so they're prevented from posting again, so it's more practical. I think it depends on the scale.

Different behaviors appear to call for different reactions, which should be carefully considered for appropriateness in context.

Participants also discussed the wisdom of ignoring trolls, as a common strategy for management embodied by the adage 'don't feed the trolls'. Participant I compared this strategy, in contrast to efforts to outsmart trolls, to handling an analogous situation of bullying:

There's the ignore them strategy, don't feed them, and then there's also, if they're obviously using very reactionary, absurd language, reply in kind. If you one up them, you piss them off. Then, therefore, you're taking power from them, but you can only do that if you really know what you're doing. Also, don't feed the troll is the same things as when someone's trying to bully you in school, by saying all of these mean things to you and you come up with a glib retort and you stump them, good you stopped them, great. If you do something back and it just makes them more angry, and they're going to continue after you anyway, you've just worsened the situation. It's a balancing act and you have to know what you're doing.

From this participant's perspective, thoughtfulness is much more effective than frustration, as it not only winds down a situation, but also is preventative.
Unmasking anonymous trolls and revealing their offline identity was described as useful technique. Participant $\mathrm{J}$ explained:

The most devastating way to deal with a troll, especially if it's online ... is to find out who they are when they're not anonymous. Like, if you do enough research on this person who's trolling you and, like, you find out this is the person's Facebook page with their real name and then you go to the board and start talking to them about their Facebook page and post the link to it, you're going to take all their power away. That's just going to completely destroy them.

This solution is possible both at the levels of the community and individuals, as a group or an individual can unmask a troll. Flexibility is an advantage to unmasking, as multiple stakeholders can operationalize this intervention and it can be done to different degrees of detail.

Creativity was highly valued by participants, as they evaluated the wisdom of particular solutions to manage trolling; many referred to specific communities, such as gaming platforms and communities. For example, participant $\mathrm{G}$ discussed the logic of the tribunal system in League of Legends:

League of Legends ... have this cool thing where after a game, you can choose to report any of the people that you played with for a variety of reasons, you know, umm, and then there's actually a player governed tribunal, it's called the tribunal, where you go online and you review these cases for, like, small rewards... it's like a peer reviewed system, like is this person actually a troll or is what they're doing acceptable. So if someone does something weird and bizarre...that's generally not reportable because you're just playing the game in a different way. Whereas the people who just try to make their teammates have a terrible time, those are the people that are reported and banned. So, it's a good system that's ... helped ... the game experience is so much better and I think, you know, it's sort of analogous to just how it should be dealt with in general.

Furthermore, this participant valued checks on peer evaluation within the system through assessment of correspondence between individual judgments and the rest of the group. The democratic nature, coupled with balances, was creative, but also uniquely appropriate to the demographics of players of this game. It was not perceived to be applicable to gaming communities with younger participants, for example, as children simply don't know how to "deal with it" (Participant G).

There may, however, be a generalizable lesson in the advantages of governance structures to appropriately manage trolling. The tribunal system and 
mechanisms for evaluation of peer reviewers represent institutionalization to support fair and uniform judgment of individual cases. In this sense, there is again flexibility, but this type of intervention is different in that it can only be applied at the community or platform level, rather than at the individual level.

Appropriateness of reaction by context is important in evaluating and formulating responses. Reddit, for example, is perceived to employ a contextual logic of appropriateness in that not all trolls are treated equally. While there are sub-communities of trolls that are permitted to persist, trolls that disrupt other Reddit sub-communities are unacceptable and viewed as being dealt with adequately:

I think Reddit's a good example of, like, when the community can do something about it. You know, the people who are dedicated trolls, they're just basically removed, you know, and that's pretty nice.

Strict rules and bright lines are viewed to be inappropriate, overall, in dealing with trolls, given the nuance of individual acts.

In summary, participants specifically identified and evaluated the circumstances in which it is appropriate to block users, delete posts, ignore users, reveal a user's true identity, employ peer evaluation through tribunal systems, or impose a governance system in response to instances of trolling. These strategies, while not an exhaustive list of possibilities, provide diverse intervention possibilities and are suitable for dealing with deviant online trolling in different contexts. While additional solutions commonly used may be valuable, the strategies discussed by participants received some level of social validation.

\subsection{Ethical concerns associated with managing trolling}

Participants explicitly considered ethical issues surrounding trolling and its management. These issues involve trolling behaviors violating ethical standards as institutionalized through honor codes or policies, as well as ethical dilemmas in responding to trolling while avoiding censorship and respecting first amendment rights.

For example, unethical trolling behaviors were discussed by Participants D and E, considering a case of trolling in an online class that explicitly contradicted the student honor code; the student-troll was penalized by reductions in grades. As participant E explained:

What I though was funny in my $[\mathrm{xxx}]$ online lecture, there was I don't know like 150 students, and there would still be people with their names, their usernames, and the Professor can see you, who still post just like the most ridiculous responses... Even with the fact that they would get like taken off their grade, they would still do it.

Participant D noted that distractors and trolls went so far beyond boundaries of acceptability as to advertise drugs for sale, within the comments. In this sense, ethical honor codes and terms of service, as institutions designed to manage behaviors, are perceived to be ineffective deterrents for online deviance. This specific example also illustrates that legal boundaries do not always deter deviant behaviors.

Participants also recognized tensions between issues of feasibility of managing trolling and ethics with respect to who would be responsible for dealing with online deviance. In response to questions about management of satirical Amazon reviews, participant $\mathrm{H}$ was particularly concerned with identification of trolls; "the thing is, is that how can Amazon discern whether he's actually being, you know," a troll. They elaborated on the difficulty of managing trolling behaviors, particularly when containing satirical elements:

it's just not time or cost efficient to try to go through every one of these to try and pick out... Because this is obviously somebody who's just very well written, there's no profanity, so it's obviously like... it's not unprofessionally written, it's just... I could see that maybe Amazon should have a responsibility over something like this, but at the same time, it's also like an ideological statement and an honest review of a book... even if Amazon was responsible for purging things like this, what, what they actually can do really... realistically, ... I just don't know how efficient that would be or how even, so...

Greater concerns are raised about protecting individual rights and not punishing people based on the perceptions or misinterpretations of others.

In particular, first amendment rights, including the freedom of speech, were cited as justification for why censorship of troll's comments would be unethical and impermissible, even when trolls push boundaries and violate expectations. Participant F explained why they felt platforms ought not to scrub evidence of trolling from their pages:

I mean it's kinda like first rights... I mean obviously I think he's trolling, but at the same time, like he can say whatever he wants to...

While there may be ways to discourage or identify trolling, such as by flagging it, and some instances of trolling may be undesirable, censoring suspected-trolls is not perceived to be acceptable.

Ethical concerns pertaining to trolling and its management, as raised by participants, can thus be 
summarized as relating to censorship and freedom of speech rights, as well as balancing these rights with feasibility and the effectiveness of formalized ethical standards.

\subsection{Complexity of managing ideological trolling}

One of the seven cases, exemplifying social and politically motivated trolling, generated particularly interesting results. The case involves pseudo-sincere and satirical Facebook posts in response to Texas Governor Rick Perry's controversial statements on women's reproductive rights. Trolls targeted Rick Perry for President page on Facebook en masse following a 2012 speech regarding a restrictive abortion bill, which was overwhelmingly opposed by both the public in Texas and physicians. In the speech Governor Perry insinuated that elected representatives better understood how to protect women's health than their opposition. Trolls comments reflected clear social and ideological motivations, mockingly sought health advice, often regarding sensitive and graphic reproductive issues, from Governor Perry. Examples of posts are presented in Figure 1. The specific case presents an interesting example; given the visibility of the campaign it has inspired subsequent coordinated responses through social media to unpopular political developments, such as the 2016 Periods for Pence campaign [e.g. 45]. Comparison of responses to this case, versus the others, not only highlights contextual specificity of appropriate responses, but also shows the complexity of managing trolling that is perceived to be socially acceptable.

Participants agreed that not all trolls alike and therefore not all trolling behaviors should be treated the same. In particular, participants expressed opinions about trolls with whom the public can sympathize and even empathize. Ideological trolls are relatable as they are expressing opinions that are motivated by social and ideological or political factors. Given the protected status of ideological and political speech and the complexity of social and political problems in society, ideological trolling is more complex, particularly from an ethical perspective, than other forms of trolling. Participants overwhelming agreed that some forms of trolling, including as represented in this scenario, are desirable and should not be discouraged. This was the case whether or not the participant agreed with the ideological opinions of Governor Perry or the trolls.

Figure 1. Trolling Governor Rick Perry's Facebook Page

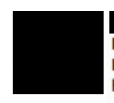

Hey Mr. Rick Perry

hear that you are particularly educated about women's reproductive health -- you are just the man I need! Before I explicate my multiple menstrual and sexual health problems, would you mind sending my a copy of your doctorate degree from the medical school you attended? I'm having a bit of trouble finding that information. Looking forward to hearing from you soon Best,

Like · Comment - 37 minutes ago - e

C 10 people like this.

Write a comment...

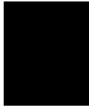

So Governor Perny,

I have a boyfriend now. Yesterday, while we were walking in the park, his hand accidentally brushed my hip. Might l be pregnant or have an appreciate if you could help me outl

Thanks,

Claire

Like - Comment - 32 minutes ago - et

25 people like this.

Write a comment.

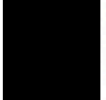

Hi rick, my husband and I are trying to get pregnant, can you give me some pointers? Since you're making decisions for uteruses everywhere, I some pointers? Since you're making
thought I'd just check in with you.

Like - Comment - 30 minutes ago - o

C3 15 people like this.

Write a comment..

As a result, recommendations in this case emphasized appeasing the trolls. Management strategies were turned toward managing the fall-out instead of trolling itself. Participants generally perceived the comments made by trolls to be more socially acceptable than the comments Governor Perry made and which precipitated the trolling event. Specifically, participant I made recommendations for Governor Perry to apologize, arguing for the following best course of action:

In this case, for him, that would be like a public statement because he's a public figure and to reply to these from the Facebook page in the normal way would just prolong the incident. So a public statement saying, "look, I'm sorry, I didn't mean to make it sound like I have any real authority to this degree. I understand. I have been told by people I trust in this field that I was wrong. I am sorry." For a public figure, you have to deal with that; you cannot reply to this one on one, it just makes you out to be more of an ass than you really need to make yourself out to be.

In this case, the implication of such a response would be to discourage continued trolling, however no burden or penalty was considered for the trolls.

There were, however, participants who also would have advised mitigating fallout by redirecting attention 
away from the trolls. This reflected an effort to allow the Governor to save face. Participant $\mathrm{H}$ advised:

I would, I mean, if I were Rick Perry I'd, or the administrator of the page, I'd try and delete all of these and maybe put out a status, you know, or something that would say like, I understand that you're concerned... try and do damage control sort of things because I mean something like this where it's a concerted effort, it's a little bit harder than just like one individual acting like a troll. So... yeah, for that I think he would have to be more proactive in trying to manage his page and ensure that he's putting out a positive message rather than fueling people mocking him.

While this advice was based on some level of sympathy for the target of the trolls, rather than the trolls themselves, it did not reflect any impulse to impose sanctions on the trolls. The burden was again placed squarely on the shoulders of the target, rather than the troll.

The overwhelming perception was that by Governor Perry's statements, he had brought the trolling event upon himself and it was deserved, rather than something to be prevented. Among participants, there was a sense that specific legitimate ideological motivations and objectives, as in this case, ought not to be punished. It is important to note, however, that this case pits the liberal, feminist ideologies of trolls against the conservative, misogynistic ideology reflected in the Governor's comments. It is possible that student perceptions, as expressed by the study participants, may have varied given different ideological distributions. It is also possible that other populations would have different opinions about the desirability of this behavior. Scholars found that people more often react negatively to polarizing comments they disagree with and conservatives react more negatively than liberals [27]. Still, our study involved both liberal and conservative participants. Furthermore, it is possible that another political issue, rather than the question on gender and sexuality [46], may have led to different perceptions.

\section{Discussion}

Appropriate responses are perceived to vary by context and behavior. Not only did participants identify distinctly different management strategies as being suitable for different platforms, but also for different populations, communities, and types of trolls. Specifically, the many levels of 'platforms' $[47,48]$, in addition to other nuances of individual interactions, generate similarities and differences between acts of trolling. In addition to technical and institutional similarities at high levels of platform, which similarly enable trolling, visibility of individual cases, as in a mass-trolling event, versus specificity of small subcommunities differentiate.

Furthermore, in the context of political trolling, participants viewed common strategies for management as flawed and favored unique and thoughtful interventions over either systematic rules or conventional wisdom. Perceptions of why someone is trolling matter when judging appropriateness of responses. Appropriateness is judged based on situational constraints [e.g. 49] in any social interaction, as well as in trolling and reactions to trolling. Ethics also come into play with respect to formation of perceptions of appropriateness and the development of institutions designed to enforce or encourage appropriate behaviors.

Dealing with socially or politically motivated instances of trolling raises concerns with respect to differences in perceived appropriateness and ethical concerns in regards to the behaviors and to the responses. Participants' concerns about balancing freedom of speech, particularly given that political speech is a protected class of speech, with normative efforts to prevent and punish trolling is significant. Even though there was consensus among our study participants that it was appropriate to communicate political opinions through trolling, others may disagree, as partisan divides in perceived appropriateness of impolite expression of ideologically extreme opinions exist [25].

Instances of trolling that are perceived by some to be desirable are complex and context dependent interventions are needed. However, it is difficult to appropriately construct individual responses or systems to structure responses, given the range of political motives that cause disagreement about appropriateness and ethical standards. While participants in this study empathized with particular trolls and their ideology, countless other studies establish context dependent responses from the perspectives of stakeholders, such as administrators, with no sympathy for trolls[e.g. 4], regardless of their motives or ideology. In this sense, the roles stakeholders play delineate between perceptions. Social role and experience in specific online communities contribute to perceptions of online trolling and appropriateness of responses [12].

The tensions demonstrated here, between recommendations, actual interventions, and the perceptions, reflect two social informatics themes associated with differences in role and experience: resistance to change and enforcement of the status quo. Drawing on social informatics literature [e.g. 50, 51], which provides an interdisciplinary perspective on interactions between people and ICTs in different 
contexts, there is evidence that technology and institutionalization around technology are often used to support existing norms and power distributions. The case of trolling Rick Perry's Facebook page is an example of the contentious nature of management of trolling and illustrates why not all interventions will be uniformly perceived as appropriate. Tension between existing norms and power distribution and effort for change clashes; online trolling pushes the boundaries of context dependent appropriateness for behaviors. This may explain why college students may approve of the case of mass trolling of Governor Rick Perry, yet administrators and certainly the governor would seek to prevent or punish these types of trolling activities.

At times, participant perceptions and recommendations supported published arguments, in particular when dealing with deviant trolling, while refuting others, specifically when dealing with political trolling. There is support for the appropriateness of unmasking troll's identity as a suitable deterrent or punishment for deviant behavior, as suggested by Suler and Phillips [36]. There is also support for more variation in responses, as has been suggested within the literature [5; 54] and popular press [e.g. 52; 53]. Additional creative recommendations were not mentioned by participants, including: creative censorship techniques, such as hell-banning or shadowbanning; employing humor to disarm them; developing barriers to social participation; tracking trolls; flagging systems; and automated interventions [5, 47, 53, 54]. It is important to further evaluate these strategies, given that they conform to participants' expressed standards for management in particular cases, yet may be inappropriate in others.

However, participant recommendations also refute claims that trolls are simply attention seeking and refusing to feed them will be effective, unlike the common narrative within the literature [e.g. 9, 55, 56]. Results also reject the idea that it is desirable to prevent all trolling, as is often assumed [e.g. 57]. Thus, it is not appropriate to treat all trolling as deviant and to uniformly punish or discourage trolling; ideological trolling adds normative, positive, and useful diversity that can push open public political discourse forward.

Management of online trolling should be context sensitive and include appropriate solutions for different platforms or communities, as well as for distinct behaviors and motivations.

\section{Conclusions}

Common perception of trolling, as deviant behavior, lead to simplistic solutions to manage these deviant behaviors. Our research examines trolling in a much broader sense, including political and ideological trolls, and thus proposes that multifaceted solutions are appropriate. Deviance has been strongly associated with trolling by the media and published works on trolling and their management. The boundaries between deviant and non-deviant are permeable as norms of behavior differ across communities. Moreover, perceptions of deviant behavior vary by context, personal experience, values, and roles. Thus, a one size fits all management solution is not effective.

This paper illustrates how appropriate interventions to manage trolling are context dependent. Participants viewed behaviors differently based on context, role, and experience, as well as the motivations and content. Cases in which ideological issues came into play, as well as cases in which issues of expression were involved, were perceived as more complex and nondeviant. Emphasis was placed, in these instances, on the need to protect individual rights to troll, as opposed of the rights of the community not to be trolled. Sentiments underlying these concerns ranged from reluctance to censor to actual onus placed on those who triggered the trolling event, rather than the troll.

Flexibility in responses to trolling is thus necessary for positive public perceptions of management. Not only should different platforms and communities have different strategies, based on expectations and institutions [5], but also individual behaviors, motivations, and interactions should be accounted for. This is particularly important when complex social and political issues are involved, rather than trolling out of boredom or for purposes of humor. Recommendations for managing online trolling range from blocking trolls or ignoring them, when the behavior was perceived as deviant, to facilitating and supporting them, when the behavior was perceived as ideologically driven.

Conclusions about the prevalence of these opinions or relative consensus about appropriateness of solutions in particular cases is unwarranted, given the limitations associated with small sample sizes. Future research should seek to test the effectiveness of particular strategies in particular contexts. For improved management of trolling behaviors scholar should identify types of trolls and motivations, so as to differentiate between circumstances in which interventions, both social and technical, are warranted.

\section{References}

[1] S. Herring, K. Job-Sluder, R. Scheckler, and S. Barab. "Searching for safety online: Managing" trolling" in a feminist forum." The Information Society, 18(5), 2002, pp.371-384. 
[2] F. Shaw. "FCJ-157 Still 'Searching for Safety Online': collective strategies and discursive resistance to trolling and harassment in a feminist network." The Fibreculture Journal, (22: Trolls and The Negative Space of the Internet), 2013.

[3] S. Nicol. " Cyber-bullying and trolling." Youth Studies Australia, 31(4), 2013.

[4] P. Shachaf, and N. Hara. "Beyond vandalism: Wikipedia trolls." Journal Of Information Science, 36(3), 2010, pp.357370 .

[5] P. Fichman, and M. R. Sanfilippo. Online Trolling and Its Perpetrators: Under the Cyberbridge. Rowman and Littlefield Publishers, 2016.

[6] Alien Entity. “Troll [Def. 1].” In Urban Dictionary, 2002. Retrieved

from http://www.urbandictionary.com/define.php?term=troll

[7] J. S. Donath. Chapter 2: Identity and deception in the virtual community. In, Communities in Cyberspace, 2002, p. 27.

[8] J. Wilson, G. Fuller, and C. McCrea. "Troll theory?" The Fibreculture Journal, (22: Trolls and The Negative Space of the Internet), 2013.

[9] A. Binns. "Don't feed the trolls!." Journalism Practice, 6(4), 2012, pp.547-562.

[10] E. E. Buckels, P. D. Trapnell, and D. L. Paulhus. "Trolls just want to have fun." Personality and Individual Differences, 2014.

[11] C. Hardaker. "Trolling in asynchronous computermediated communication: From user discussions to academic definitions." Journal Of Politeness Research-Language Behaviour Culture, 6(2), 2010, pp.215-242.

[12] M. R. Sanfilippo, S. Yang, and P. Fichman. "Public Perceptions of Trolls.” (in preparation).

[13] S. C. Herring, S. Barab, R. Kling, and J. Gray. "An approach to researching online behavior." Designing for virtual communities in the service of learning, 338, 2004.

[14] J. Gebauer, J. Füller, and R. Pezzei. "The dark and the bright side of co-creation: Triggers of member behavior in online innovation communities." Journal of Business Research, 66(9), 2013, pp.1516-1527.

[15] J. Bishop. "Trolling for the Lulz?." Transforming Politics and Policy in the Digital Age, 2014, pp.155.

[16] P. Fichman, and M. R. Sanfilippo. "The Bad Boys and Girls of Cyberspace: How Gender and Context Impact Perception of and Reaction to Trolling." Social Science Computer Review, 33(2), 2015.
[17] B. Danet. "Flaming and linguistic impoliteness." In: Herring, S. C., Stein, D. and Virtanen, T., Eds. (2013). Handbook of pragmatics of computer-mediated communication. Berlin: Mouton. 2013.

[18] T. Karppi. "Change name to No One. Like people's status' Facebook Trolling and Managing Online Personas. The Fibreculture Journal, (22: Trolls and The Negative Space of the Internet), 2013.

[19] T. Jordan, and P. Taylor. "A sociology of hackers." Sociological Review, 46(4), 1998, pp.757-780.

[20] J. W. Kelly, D. Fisher, and M. Smith. "Friends, foes, and fringe: norms and structure in political discussion networks." In Proceedings of the 2006 international conference on Digital government research (dg.o '06). Digital Government Society of North America, 2006, pp.412-417.

[21] S. Downing. "Attitudinal and behavioral pathways of deviance in online gaming." Deviant Behavior, 30(3), 2009 pp.293-320.

[22] W. Phillips. "LOLing at tragedy: Facebook trolls, memorial pages and resistance to grief online." First Monday, 16(12), 2011.

[23] W. Phillips. This is why we can't have nice things: Mapping the relationship between online trolling and mainstream culture. Cambridge, MA: The MIT Press, 2015.

[24] S. Krappitz. Troll culture. Dissertation. 2012.

[25] M. T. Whitty. "The realness of cybercheating: Men's and women's representations of unfaithful internet relationships." Social Science Computer Review, 23(1), 2005, pp.57-67.

[26] B. Kirman, C. Lineham, and S. Lawson. "Exploring mischief and mayhem in social computing or: how we learned to stop worrying and love the trolls." In Proceedings of the 2012 ACM annual conference extended abstracts on Human Factors in Computing Systems Extended Abstracts (CHI EA '12). 2012.

[27] E. Suhay. "The polarizing effect of incivility in the political blog commentsphere." American Political Science Association 2013 Annual Meeting Paper, 2013.

[28] T. Casti. "John Oliver's army of Internet trolls broke a government website." The Huffington Post, June 3, 2014. http://www.huffingtonpost.com/2014/06/03/john-oliverbroke-the-fcc-

website_n_5439694.html?utm_hp_ref=comedyandir=Comed y

[29] N. Sonnad. "An army of Chinese trolls has jumped the Great Firewall to attack Taiwanese independence on Facebook." Quartz. 2016. Retrieved from http://qz.com/598812/an-army-of-chinese-trolls-has-jumped- 
the-great-firewall-to-attack-taiwanese-independence-onfacebook/

[30] B. Burroughs. "FCJ-165 Obama Trolling: Memes, Salutes and an Agonistic Politics in the 2012 Presidential Election." The Fibreculture Journal, (22: Trolls and The Negative Space of the Internet), 2013.

[31] S. Holmes. “ FCJ-160 Politics is Serious Business: Jacques Rancière, Griefing, and the Re-Partitioning of the (Non) Sensical." The Fibreculture Journal, (22: Trolls and The Negative Space of the Internet), 2013.

[32] A. McCosker, and A. Johns. "FCJ-161 Productive Provocations: Vitriolic Media, Spaces of Protest and Agonistic Outrage in the 2011 England Riots." The Fibreculture Journal, (22: Trolls and The Negative Space of the Internet), 2013.

[33] T. Higgin. "FCJ-159/b/lack up: What Trolls Can Teach Us About Race." The Fibreculture Journal, (22: Trolls and The Negative Space of the Internet), 2013.

[34] K. Gorton, and J. Garde-Hansen. "From Old Media Whore to New Media Troll: The online negotiation of Madonna's ageing body." Feminist Media Studies, 13(2), 2013, pp.288-302.

[35] A. Massanari. "\#Gamergate and The Fappening: How Reddit's algorithm, governance, and culture support toxic technocultures." New Media \& Society, 2015.

[36] J. R. Suler, and W. L. Phillips. "The bad boys of cyberspace: Deviant behavior in a multimedia chat community." CyberPsychology and Behavior, 1(3), 1998, pp.275-294.

[37] K. Bergstrom. ""Don't feed the troll": Shutting down debate about community expectations on Reddit.com." First Monday, 16(8), 2011.

[38] A. Gammon. "Over a quarter of Americans have made malicious online comments." YouGov, October 20, 2014. https://today.yougov.com/news/2014/10/20/over-quarteramericans-admit-malicious-online-comm/

[39] Z. Birchmeier, A. Joinson, A., and B. Dietz-Uhler. "Storming and forming a normative response to a deception revealed online." Social Science Computer Review, 23(1), 2005, pp.108-121.

[40] M. Clemmett, " Hacktivism: Computer hacking: Can "good" hackers help fight cybercrime?" CQ Researcher, 21(32), 2011, pp.771.

[41] M. Dunning. "Minimizing risks of cyber activism." Business Insurance, 46(10), 2012, pp.4-20.

[42] J. Morahan-Martin. "Internet abuse: Addiction? Disorder? Symptom? Alternative explanations?" Social Science Computer Review, 23(1), 2005, pp.39-48.
[43] B. Saporito. "Hack attack." Time, 178(1), 2011, pp.5055 .

[44] G. Coleman. Hacker, hoaxer, whistleblower, spy: The many faces of Anonymous. Verso Books. 2014.

[45] M. Smith. “"Periods for Pence' campaign targets Indiana Governor over abortion law." New York Times, April 7, 2016. Retrieved from http://www.nytimes.com/2016/04/08/us/periods-for-pencecampaign-targets-indiana-governor-over-abortion-law.html

[46] K. Sanbonmatsu. Democrats, Republicans and the Politics of Women's Place. Ann Arbor: University of Michigan Press, 2003.

[47] K. Crawford, \& T. Gillespie. "What is a flag for? Social media reporting tools and the vocabulary of a complaint." New Media \& Society, 2014, 1-19.

[48] T. Gillespie. "The politics of "platforms"." New Media \& Society, 12(3), 2010, 347-364.

[49] R. H. Price, and D. L. Bouffard. "Behavioral appropriateness and situational constraint as dimensions of social behavior." Journal of Personality and Social Psychology, 30(4), 1974, pp.579.

[50] R. Kling. "What is social informatics and why does it matter?.” The Information Society, 23(4), 2007, pp.205-220.

[51] P. Fichman, M. R. Sanfilippo, and H. Rosenbaum. "Social Informatics Evolving." Synthesis Lectures on Information Concepts, Retrieval, and Services, 7(5), 2015.

[52] H. Allner. "Online comment sections are terrible: Monetizing them would make them worse." Fast Company. $2016 . \quad$ Retrieved from http://www.fastcompany.com/3059870/would-paid-forcomments-improve-online-discourse-or-ruin-it-more

[53] A. Costill. "10 ways to destroy an online commenting troll." The Search Engine Journal. January 14, 2014. Retrieved from http://www.searchenginejournal.com/10ways-destroy-online-commenting-troll/84427/

[54] A. Weckerle. Civility in the Digital Age: How Companies and People Can Triumph over Haters, Trolls, Bullies and Other Jerks. Que Publishing. 2013.

[55] K. Bergstrom. "A troll by any other name: Reading identity on Reddit.com." Association of Internet Researchers - ir11, Gothenburg, Sweden: October 21-23, 2010.

[56] R. MacKinnon, and E. Zuckerman. "Don't feed the trolls.” Index on Censorship, 41(4), 2012, pp.14-24.

[57] K. Richardson. "Don't feed the trolls: Using blogs to teach civil discourse." Learning and Leading With Technology, 35(7), 2008, pp.12-15. 